\title{
REGULATION OF CELLULAR IMMUNE RESPONSE BY NATURALLY OCCURRING PRODUCTS ON HEPATOCELLULAR CARCINOMA
}

\author{
Mohammed Banawy, Shaden M. Hanafy and Hany Khalil* \\ Department of Molecular Biology ,Genetic Engineering and Biotechnology Research Institute , \\ University of Sadat City, Egypt \\ *Corresponding author: hkhalil74@gmail.com
}

\begin{abstract}
Hepatocellular carcinoma (HCC) is the most important case of liver cancer disease particularly in Egypt. On the other hand, autophagy plays critical role in cellular immune response in different disease including cancer. Notably autophagosome formation required different proteins interaction for initiation, elongation and maturation steps known as Atg proteins. Additionally, tumor suppressor gene including P53 gene play regulatory role in cells proliferation and cell division, down regulation of P53 gene leads to improvement of carcinogenic cells and enhancement of cell proliferation. Here we aim to investigate the possible connection between P53 gene expression and autophagic machinery on HCC upon treatment with some naturally occurring products using HepG2 cell lines. Our findings indicate that, treatment with Guava leafs and Guava flowers extraction increase the expression profile of P53 gene and reduce autophagosome formation indicated by LC3 gene expression. Conversely, the treatment of guava leafs and guava flower extraction on normal cell (normal melanocyte) stimulate autophagic machinery with neutral influence on P53 expression without any detectable cytotoxic effect. Collectively, the natural product from guava leafs and flowers regulate cell proliferation via inhibition of autophagosome formation associated with activation of p53 signaling pathway in HCC. These findings strongly indicate that the indicated nature products can be attractive candidates in therapeutically strategy for liver cancer development.
\end{abstract}

Keywords: Hepatocellular carcinoma, autophagy, apoptosis, natural products

\section{INTRODUCTION}

Hepatocellular carcinoma (HCC) also called malignant hepatoma) is the most common type of liver cancer in Egypt, Asia and sub-Saharan Africa (Munoz N, Linsell A 1982). $\mathrm{HCC}$ is also an important cause of human mortality worldwide. HCC is considered as the fifth commonest cause of malignancy and the third cause of cancer mortality (Schutte et al 2009 and Thun et al 2010). HCC disease occurs in the patients with liver cirrhosis mainly related to hepatitis $B$ and $C$ infections, hemochromatosis, alcohol consumption, non alcoholic steatohepatitis person, nitrosamines and aflatoxins (Beasley et al 1981 and Kumar 2003). On the other hand, the innate immune system, is the secondary line of defense, comprises the cells and mechanisms that defend the host from infection by other organisms in a non-specific manner. This means that the cells of the innate system recognize and respond to pathogens in a generic way, but unlike the adaptive immune system, it does not confer long-lasting or protective immunity to the host. Innate immune systems provide immediate defense against infection, and are found in all classes of plant and animal life (Albert, 2010). For instance, autophagy is a double membraned vacuoles responsible for degradation events in cellular cytoplasm via biding with lysosomes. Autophagy usually degrade microorganisms (such as viruses, bacteria and protozoa) that invade intracellular (Deretic et al., 2009 ; Virgin HW, Levine B 2009). Cellular autophagy involves the sequestration of regions of the cytosol within double-membrane-bound compartments that then mature and degrade their cytoplasmic contents. Autophagy 
mechanism start with the formation of double-membrane vesicles, known as autophagosomes, that engulf cytoplasmic constituents. The autophagosomes then bind with lysosomes, where the sequestered contents undergo degradation and recycling (Degenhardt et al., 2006). The first step in autophagic machinery is the initiation step in which Atg5 and Atg12 are conjugated and associated together, then in elongation step conversion of cytosolic LC3 to membraned LC3 is a essential in order to complete the autophagosome formation (Tanida et al ., 2008). Finally, the maturation step in which autophagy is completed and the double membraned vacuoles is performed. Importantly, delivering of autophagosome and its content to lysosome is required to degradation and recycling step of unnecessary protein producing autolysosome; the degradation products are released in the cytoplasm and can be reutilized or become an energy source (Xie et al., 2007 ; Chen et al., 2011 ; Zeng et al.,2012). Autophagy is controlled by mammalian target of rapamycin (mTOR), which is a serine/threonine protein kinase that acts as a central regulator of cell growth and survival, by the action of class I phosphatidylinositol 3-kinase (PI3K)( Rusten et al.,2004),Class I PI3K activates Akt1, which is another serine/threonine protein kinase located downstream of class I PI3K, and stimulates mTOR, leading to suppression of autophagy (Petiot et al., 2000; Meijer 2004). The autophagy function is presumably to maintain cellular homeostasis in conditions of low content of cellular nutrient supplies and other metabolic perturbations(e.g., hypoxia). autophagy is induced in tumor cells within hypoxic tumor regions(Mazure NM ,Pouyss 2010). The role of Autophagy in cancer is to survive the cell proliferation. Autophagy machinery is the path way that enable the tumor cells to survive under adverse conditions ( Degenhardt et al.,2006). Tumor suppressor genes are normal genes that slow down cell division, repair DNA mistakes, cell cycle arrest, or tell cells when to die (a process known as apoptosis or programmed cell death) (Beyza et al., 2012). When tumor suppressor genes don't work properly, cells can grow out of control, which can lead to cancer. Tumor suppressor genes have protective functions that limit the growth of tumors and regulate many cellular activities (Sherr and C. J 2004). P53 activates other genes to regulate cell cycle arrest, cellular senescence, and apoptosis in response to various signals (Huang et al .,2000). P53 is regulated by external and internal stress signals that lead to its nuclear up regulation in an active form. The $\mathrm{p} 53$ protein up regulated and activated in response to a number of stressful stimuli including exposure of cells to DNA damaging agents, nucleotide depletion, hypoxia, or oncogenes activation (El-Deiry 1998). In turn, p53 protein induces either viable cell growth arrest or apoptosis. The growth suppression role of $\mathrm{p} 53$ prevent the proliferation of cells with damaged DNA or with a potential for neoplastic growth . p53 have role in cellular processes such as, DNA repair and angiogenesis, differentiation which also re important for tumor suppression (Haupt et al.,1995; Vogt et al2001).

p53 governs an essential growth checkpoint that both protects against genomic rearrangement or the accumulation of mutations, and suppresses cellular transformation caused by oncogene activation or the loss of tumour suppressor pathways(Levine AJ: p53, the cellular gatekeeper for growth and division. Cell 1997, 88:323-331).

\section{Natural product}

natural products (NPs) are chemical compounds or substances that produced by a living organism found in nature (Samuelson G 1999and Cutler SJ, Cutler HG2000 ). living organism may be plant or fungi, microbes, and marine organisms (Baker DD et al 2007). (NPs) play a very important role in anticancer drug discovery and a much of NPs have potential anticancer effects . the use of natural product of plant was used from several thousand years ago in ancient Egypt, 
ancient China and ancient Roma. current research center of attention on increasing interest the major benefits about natural product for human (Marginâ D et al 2015) . (NPs) show a good source for cancer treatment because their absorption and metabolism in the body with low toxicity and good effect on cancer cell in comparison between it and synthesized chemical compounds. and we use a group of natural product and their effect on human normal melanocyte and Hepatocellular carcinoma cell line( hepg2)

there are a lot of (NP) that have effevt on HCC like that Black seed (Nigella sativa) is considered has agood effect on HCC, Thymoquinone (TQ) is the bioactive

\section{Figure 1}

A

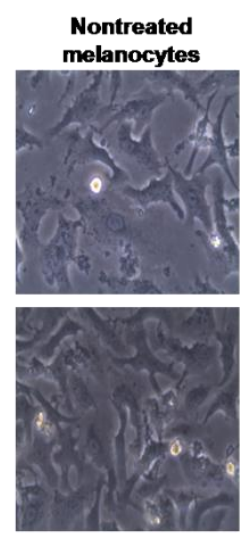

Nontreated melanocytes

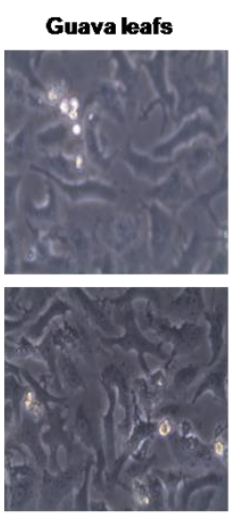

lemon leafs

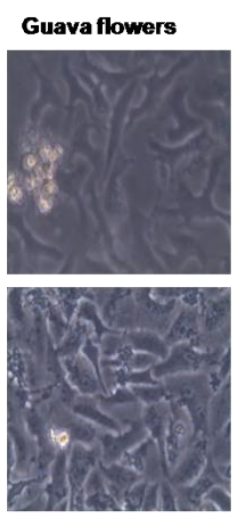

lemon flowers compound in Black seed, the effect of TQ on HepG2 cell line through induced apoptosis it(Hassan et al .,2008).curcumin bound BSA has a strong inhibitory activity against tumors ,A significant reduction in anti-oxidants and tumor markers levels in tumor treated animals when compared with untreated ones. As well as the level of $\mathrm{Bcl} 2$ was reduced(Faten et al.,2014)

\section{Material and method}

cell line treatment + PCR

statistical analysis

\section{Results}

Normal cell
B

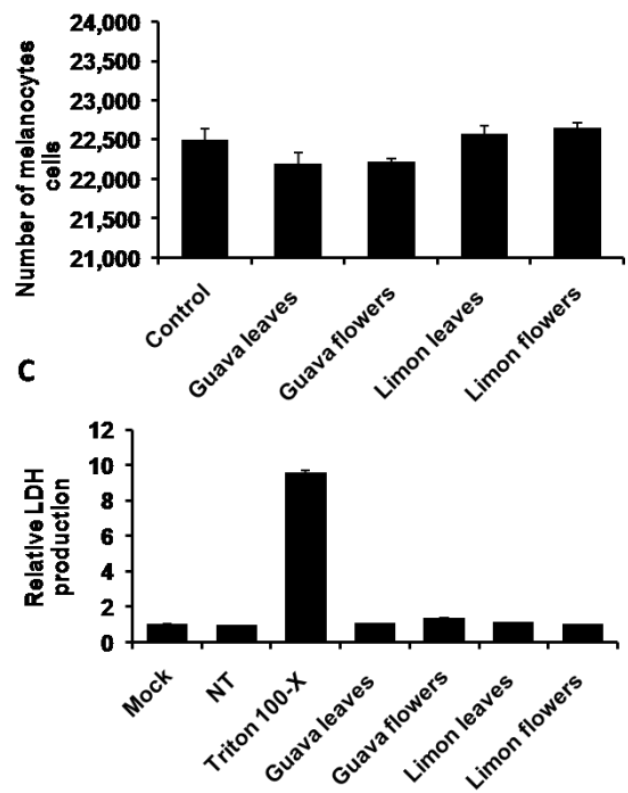

figure 1 effect if natural product on melanocyte cell

(a) The image of melanocyte cells treated with the indicated natural by using inverted microscope (20x).

(b) Number of melanocytes cell upon treatment with indicated product . error bars indicate standard division of two in depended experiments .

(c) Relative LDH production from treated cell compared to Triton $\mathrm{X}$ treated cells . error bars indicate standard division of two in depended experiments

the indicated natural product have no cytotoxic effect on normal cell (melanocyte ). 


\section{Figure 2}

A
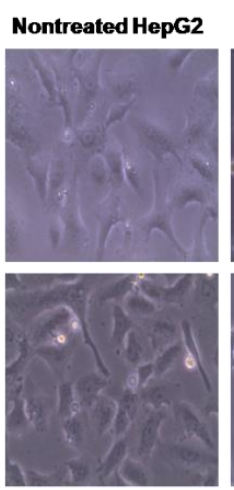

Nontreated HepG2
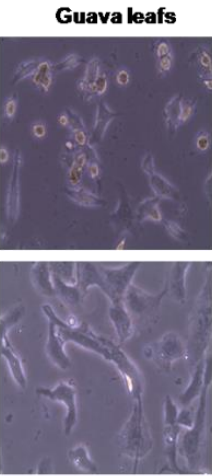

Lemon leafs
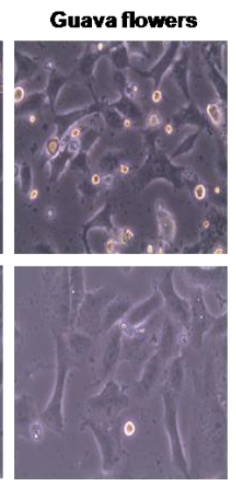

Limon flowers
B

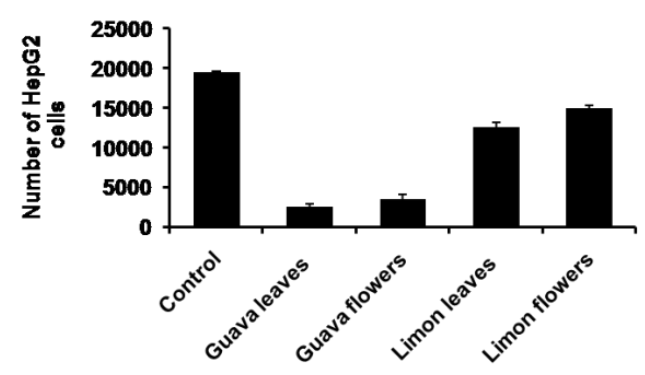

C

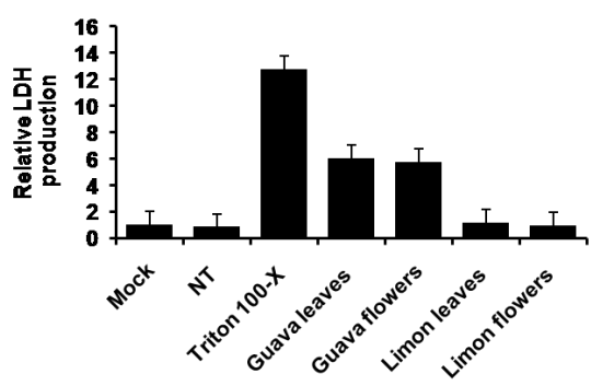

Effect of natural product on Hepatocellular carcinoma (HepG2)

(a) The view of Hepg2 cells treated with indicated natural product by using inverted microscope (20x) .

(b) number of Hepg2cell upon treatment with indicated product . error bars indicate standard division of two in depended experiments.

(c) Relative LDH production from treated cell compared to Triton X treated cells . error bars indicate standard division of two in depended experiments

the indicated some natural product have cytotoxic effect on Hepg2 cell line . 
Figure 3

A

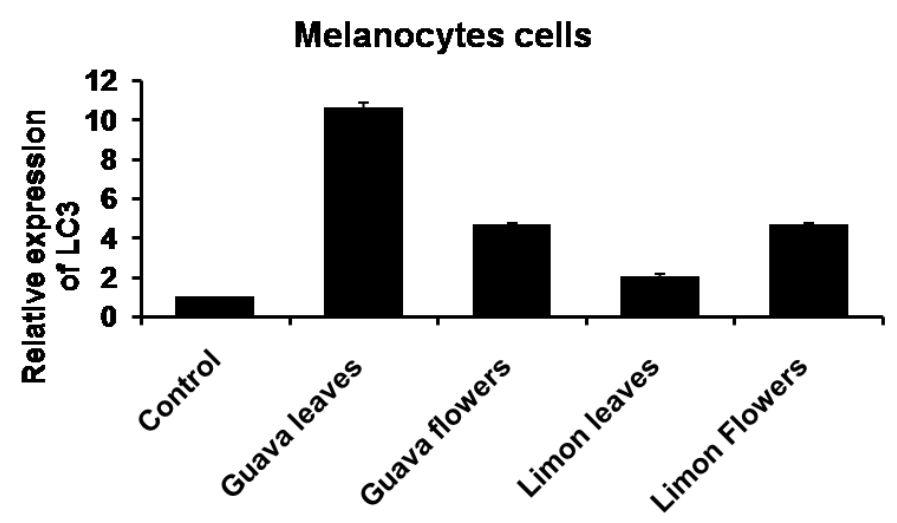

B

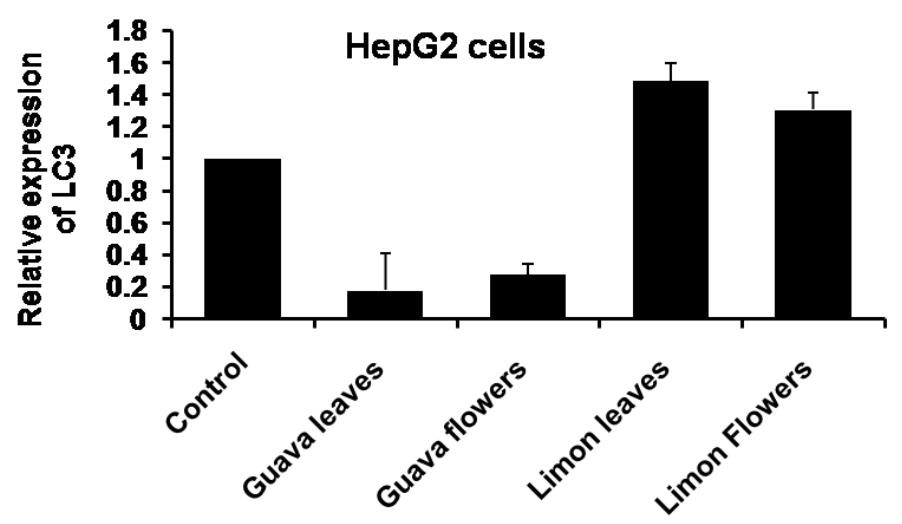

\section{Autophagosome formation}

(a) The image show LC3 expression in normal melanocytes cell line after treated with indicated natural products.

(b) The view of LC3 expression in Hepg2 cell line after treated with indicated natural products .

The LC3 gene is biomarker for autophagosome formation . 
Figure 4

$\mathbf{A}$
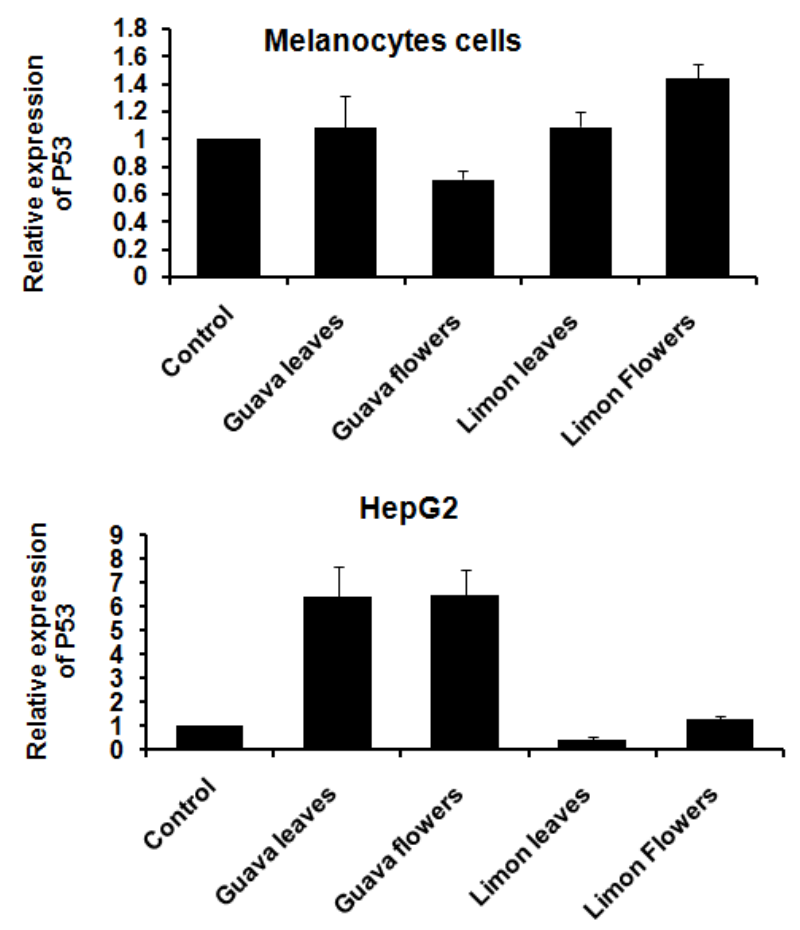

\section{Induction of Apoptosis}

(a) The image show the relative expression of P53 gene in normal melanocyte after treated with previous natural products.

(b) The image show the amount of P53 gene expression in Hepg2 cell line after treated with indicated natural products .

The P53 gene is bio marker for induction of apoptosis . 


\section{Discussion}

Autophagy increase only in cancer cell and survive the cell content and protect it from Apoptosis and tumor suppressor gene. Autophagy has reverse relationship with Apoptosis and P53.if we make inhibition to Autophagy the Apoptosis and tumor suppressor gene will increase . and if we make induction to the Apoptosis or tumor suppressor gene the Autophagy will decreased . and then we discovered this natural product that lead to increase the expression of tumor suppressor gene which responsible the Apoptosis and inhibition of Autophagy only in (cancer cell).

\section{REFERENCE}

Alberts,B. (2010). Cell biology: the endless frontier. Mol. Biol. Cell 21, 3785.

Bartsch H, Montesano R. Relevance of nitrosamines to human cancer.Carcinogenesis 1984;5:1381-93.

Kensler TW, Egner PA, Wang JB, Zhu YR, Zhang BC, Lu PX, Chen JG, Qian GS, Kuang SY, Jackson $P E$, Gange SJ, Jacobson LP, Muñoz A, Groopman JD. Chemoprevention of hepatocellular carcinoma in aflatoxin endemic areas. Gastroenterology 2004;127:S310-8).

Munoz N, Linsell A. Epidemiology of primary liver cancer. In: Correa P. Haenszel W, eds. Epidemiology of Cancer of the Digestive Tract. The Hague: Martinus Nijhoff, 1982; 161-195

Schutte K, Bornschein J, Malfertheiner P. Hepatocellularcarcinoma-epidemiological trends and risk factors. Dig Dis 2009;27:80-92).

Thun MJ, DeLancey JO, Center MM, Jemal A, Ward EM. The global burden of cancer: priorities for prevention. Carcinogenesis 2010;31:100-10).

Kumar V, Fausto N, Abbas A (editors) (2003). Robbins \& Cotran Pathologic Basis of Disease (7th ed.). Saunders. pp. 914-7

Cutler SJ, Cutler HG. Biologically active natural products: pharmaceuticals. Boca Raton: CRC Press; 2000

Samuelson G. Drugs of natural origin: a textbook of pharmacognosy. New York: Taylor and Francis Ltd.; 1999
Baker DD, Chu M, Oza U, Rajgarhia V. The value of natural productsto future pharmaceutical discovery. Nat Prod Rep 2007;24:1225-44

Marginâ D, llie $M$, Grâdinaru D, Androutsopoulos VP, Kouretas D, Tsatsakis AM. Natural products-friends or foes? Toxicol Lett 2015;236:154-67 .

Jemal, A.; Bray, F.; Center, M.M.; Ferlay, J.; Forman, D. Grobal cancer statistics. CA Cancer J. Clin. 2001, 61, 69-90.

Beasley RP, Hwang LY, Lin CC, et al. Hepatocellular carcinoma and hepatitis $B$ virus. A prospective study of 22707 men in Taiwan. Lancet. 1981 Nov 21. 2(8256):1129-33 Kumar V, Fausto N, Abbas A (editors) (2003). Robbins \& Cotran Pathologic Basis of Disease (7th ed.). Saunders. pp. 914-7

Mizushima, N.; Levine, B. Autophagy in mammalian development and differentiation. Curr. Opin. Cell Biol. 2010, 22, 177?180.

(Degenhardt K, Mathew R, Beaudoin B, Bray K, Anderson D, Chen G, et al. Autophagy promotes tumor cell survival and restricts necrosis, inflammation, and tumorigenesis. Cancer Cell 2006;10:51-64)

Deretic V, Levine B. Autophagy, immunity, and microbial adaptations. Cell Host Microbe. 2009;5:527-549

Virgin HW, Levine B. Autophagy genes in immunity. Nature Immunol. 2009;10:461-470 
Degenhardt K, Mathew R, Beaudoin B, Bray K, Anderson D, Chen $G$, et al. Autophagy promotes tumor cell survival and restricts necrosis, inflammation, and tumorigenesis. Cancer Cell 2006;10:51-64).

Mazure NM, Pouyss_egur J. Hypoxia-induced autophagy: cell death or cell survival? Curr Opin Cell Biol 2010;22:177-80

Xie, Z.; Klionsky, D.J. Autophagosome formation: Core machinery and adaptations. Nat. Cell Biol. 2007, 9, 1102?1109.

Chen, Y.; Klionsky, D.J. The regulation of autophagy-unanswered questions. J. Cell Sci. 2011,124, 161?170

Zeng, Y.; Yang, X.; Wang, J.; Fan, J.; Kong, Q.; $\mathrm{Yu}, \mathrm{X}$. Aristolochic acid I induced autophagy extenuates cell apoptosis via ERK $1 / 2$ pathway in renal tubular epithelial cells. PLoS One 2012, 7, e30312

Scott RC, Schuldiner O, Neufeld TP. Role and regulation of starvation-induced autophagy in the Drosophila fat body. Dev Cell 2004;7:16778. [PubMed: 15296714]

Degenhardt K, Mathew R, Beaudoin B, Bray K, Anderson D, Chen $G$, et al. Autophagy promotes tumor cell survival and restricts necrosis, inflammation, and tumorigenesis. Cancer Cell 2006;10:51-64).

(Huang, D. C. and Strasser, A. (2000). BH3Only proteins-essential initiators of apoptotic cell death. Cell 103, 839-842).

El-Deiry WS _1998. Review: the p53 pathway and cancer therapy. The Cancer J 11:229]236.

Hassan SA, Ahmed WA, Galeb FM, El-Taweel MA and Abu-Bedair FA / IJPR (2008), 7 (4): 283-290

Faten Zahran, Essam Mady, Osama Yasein, Akaber T. Keshta November 25, 2014 Science Signpost Publishing
Rusten TE, Lindmo K, Juhasz G, Sass $M$, Seglen $\mathrm{PO}$, Brech $\mathrm{A}$ and Stenmark $\mathrm{H}$ : Programmed autophagy in the Drosophila fat body is induced by ecdysone through regulation of the PI3K pathway. Dev Cell 7: 179-192, 2004.

Petiot A, Ogier-Denis E, Blommaart EF, Meijer AJ and Codogno P: Distinct classes of phosphatidylinositol 3'-kinases are involved in signaling pathways that control macroautophagy in HT-29 cells. J Biol Chem 275: 992-998, 2000.

Meijer AJ and Codogno P: Regulation and role of autophagy in mammalian cells. Int J Biochem Cell Biol 36: 2445-2462, 2004.

Tanida I, Ueno T, Kominami E: LC3 and Autophagy Methods Molecular Biology. 2008;445:77-88. doi: 10.1007/978-159745-157-4_4.

Vogt Sionov, R., Hayon, L. I. and Haupt, Y. (2001). The regulation of p53 growth suppression. In Cell Cycle Checkpoints and Cancer (ed. M. V.Blagosklonny), pp. 106-125. Georgetown, Texas: Austin Landes Bioscience.

Haupt, Y., Rowan, S., Shaulian, E., Vousden, K. H. and Oren, M. (1995). Induction of apoptosis in HeLa cells by trans-activation-deficient p53. Genes Dev. 9, 2170-2183.

Beyza Vurusaner, Giuseppe Poli , Huveyda Basaga Tumor suppressor genes and ROS Free Radical Biology \& Medicine 52 (2012) 7-18

Sherr, C. J. Principles of tumor suppression. Cell 116:235-246; 2004. 